\title{
Full-scale modeling tests and numerical simulation of infilling behavior of plastic grout
}

\author{
Hiroyasu Ishii ${ }^{\text {i) }}$ and Masaki Kitazume ${ }^{\text {ii) }}$
}

i) Senior Research Engineer, Technology Center, TAISEI Co., Ltd., 344-1, Nase-cho, Totsuka-ku, Yokohama, 245-0051, Japan. ii) Professor, Department of Civil Engineering, Tokyo Institute of Technology, 2-12-1, Oookayama, Meguro-ku, Tokyo, 152-8552, Japan.

\begin{abstract}
Infilling of underground voids using a cement mixture is an effective measure to prevent the collapse of old mines, or to restore the ground reaction against overlying foundations. Normally a slurry mixture with high workability is placed into a void under gravity allowing a wide areas to be filled effectively from a single pouring point. However a different type of mixture, a plastic grout, is needed when only limited area is to be filled or where mixtures spillage would lead to problems. The aim of this study is to better understand the behavior of plastic infilling material in the quest for greater reliability in actual work. Two full-scale model tests using plastic grout are described with the spreading pattern and infilling pressure experimentally and numerically assessed. The first test involved filling a $5 \mathrm{~m}$ by $7 \mathrm{~m}$ void of $500 \mathrm{~mm}$ height with plastic grout in a single filling step. In the second test, $2.6 \mathrm{~m}$ by $3.0 \mathrm{~m}$ void of $200 \mathrm{~mm}$ height, was filled in two steps. Both the tests were numerically simulated, with results that quantitatively recreated the experimental infilling pressures.
\end{abstract}

Keywords: infilling, plastic grout, cement, maintenance and repair, numerical fluid analysis

\section{INTRODUCTION}

Underground voids are one of the geotechnical risks of urban life and construction work. Such voids may be old mines, abandoned adits and spaces beneath foundations induced by sand washout or ground settlement. An effective measure to prevent collapse of the grounds surrounding voids and restore the reaction of the ground against foundations is to infill the space with a cement mixture.

Normally a slurry mixture with high workability is used so that placement under gravity will have a wide reach from each pouring point. This minimizes the number of pouring points, resulting in a shorter construction period and reduced costs. However a different type of mixture, a plastic grout, is needed when only limited area is to be filled without form-work, or spillage is unacceptable.

The aim of the present study is to understand the behavior of plastic grout, and leading to improve reliability in actual work. The voids studied in this research were $200-500 \mathrm{~mm}$ in height and $2-7 \mathrm{~m}$ in extent based on the purpose to study infilling beneath level foundations.

This paper first defines the plastic grout, which has different characteristics from conventional grouts and mortars. Then two full-scale modeling tests using plastic grout are reported, in which the spreading shapes of the infilling and inlet pressure are experimentally observed. Finally, the tests are numerically assessed to examine the applicability of the numerical methods to the estimation of actual work.

\section{PLASTIC GROUT}

A typical plastic grout consists of cement, water and a plasticizing agent, such as a sodium silicate or clay minerals. Such grouts have recently been used in construction work as an effective method for infilling (Sakamoto et al. (2006), Yasui et al. (2011), Ohtani et al. (2014)). As shown in Fig. 1, plastic grout holds its shape when there is no inlet pressure, but readily moves forward when subjected to inlet pressure. The fresh flowability is normally checked by a flow test using a cylindrical casing measuring $80 \mathrm{~mm}$ in both height and diameter. Typical flow of the plastic grout are 80 - 120 $\mathrm{mm}$ in contrast with $200 \mathrm{~mm}$ or more for conventional workable mixtures. As illustrated in Fig. 2, the plastic grout is pushed forward by the following mass when injected into voids, which is different from the flow behavior seen with conventional gravity placement. As a result, the voids can be filled to full height with a lower probability of leaving major voids.

The plastic grout is first prepared in separate solutions: cement solution and plasticizer solution; these are pumped separately from the plant to the infilling work place, then mixed together immediately before infilling. This procedure enables delivery by pipe over a long-distance, because the viscosity of each solution is less than that of the plastic grout itself so a 

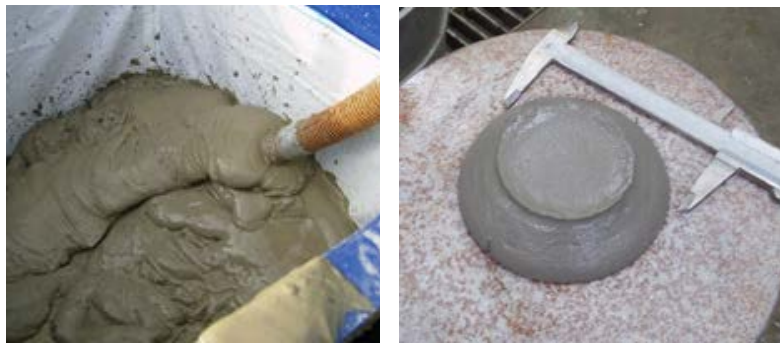

Fig. 1. Plastic grout.

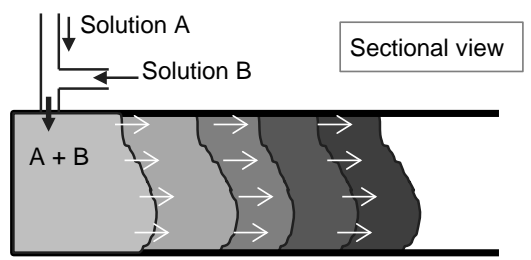

Fig. 2. Infilling behavior of plastic grout.

lower pumping pressure is required. During the maturing period, the grout hardens with the help of cement hydration to reach an unconfined compressive strength of approximately $1 \mathrm{MN} / \mathrm{m}^{2}$ or more according to the mix design.

\section{INFILLING TESTS}

\subsection{Test 1: infilling from single inlet}

This test was conducted in a large circular water tank with a diameter of $9 \mathrm{~m}$, as shown in Fig 3. It was planned in advance of a site application, where plastic grout was to be used in construction of an immersed tunnel foundation (Ishii et al. (2011), Ito et. al. (2011)). The void to be filled was prepared as follows. Firstly, road decking panels were placed in the water tank. Then cobbles were spread and a mound was created in the middle of the long axis, with reference to site conditions. A model slab measuring $5 \mathrm{~m}$ by $7 \mathrm{~m}$ in plan was then fixed in place, leaving a gap of $500 \mathrm{~mm}$ above the cobble foundation. An inlet and an outlet, both of $50 \mathrm{~mm}$ size, were then installed on the longer axis, at a distance of $500 \mathrm{~mm}$ from the edges.

Plastic grout having approximately $100 \mathrm{~mm}$ flow was injected through the inlet until it filled the entire space under submerged condition. The injection rate was set at $300 \mathrm{~L} / \mathrm{min}$ with reference to site plan. A total volume of $15 \mathrm{~m}^{3}$ was supplied in 50 minutes.

In order to confirm the arrival of the plastic grout, thermo couples were installed on the bottom surface of the model slab at 16 points as indicated in Fig. 3. Grout arrival was detected by a change in the measured temperature, which was possible because the plastic grout was slightly warmer than the surrounding water owing to the effect of cement hydration.

Once infilling had started, it was observed through the transparent panels on the model slab that the grout expanded generally in a circular direction, finally reaching the outlet. After the grout had set, the model

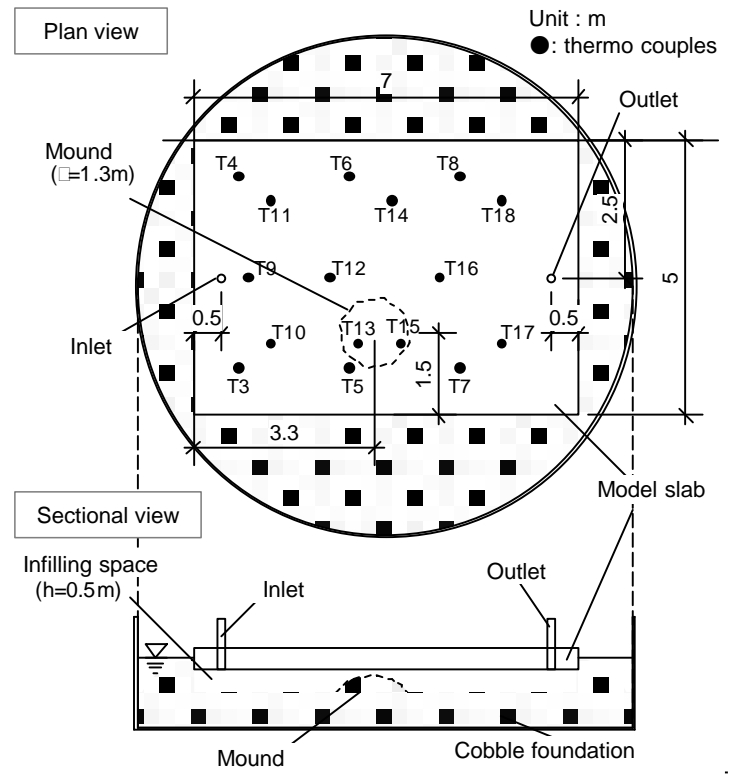

Fig. 3. Plan and sectional view of Test 1 .
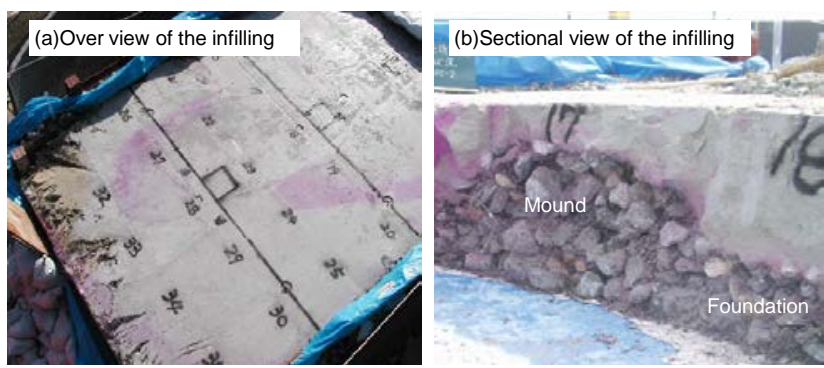

Fig. 4. Observations after removal of model slab in Test 1.

slab was removed to observe the infilling result. The surface of the grout was found to be fully flat without even minimal voids, as shown in Fig. 4(a). Further visual inspections during post removal work confirmed good infilling throughout, as depicted in Fig. 4(b).

Grout arrival times and change in inlet pressure are illustrated and discussed in the next chapter along with the numerical assessment.

\subsection{Test 2: step infilling from two inlets}

The test was conducted to demonstrate placing partitions which separate infilling space and outer space with height of $200 \mathrm{~mm}$, as illustrated in Fig. 5. This partition contributes the use of high workable mortar to infill the space without spilling out. This way to use the plastic grout was adopted to infill the space beneath a piled slab (Ohtani et. al. (2014)).

The infilling space was covered by the wooden panels to maintain the $200 \mathrm{~mm}$ height, and surrounded and fixed using steel beams.

Infilling was conducted in two steps at a $40 \mathrm{~L} / \mathrm{min}$ supply rate. The first infilling was through the $50 \mathrm{~mm}$ inlet at one corner of the space. It was carried out in air using the grout having approximately $100 \mathrm{~mm}$ flow and progress was directly observed during the work as shown in Fig. 6. Infilling was continued until the tip of 


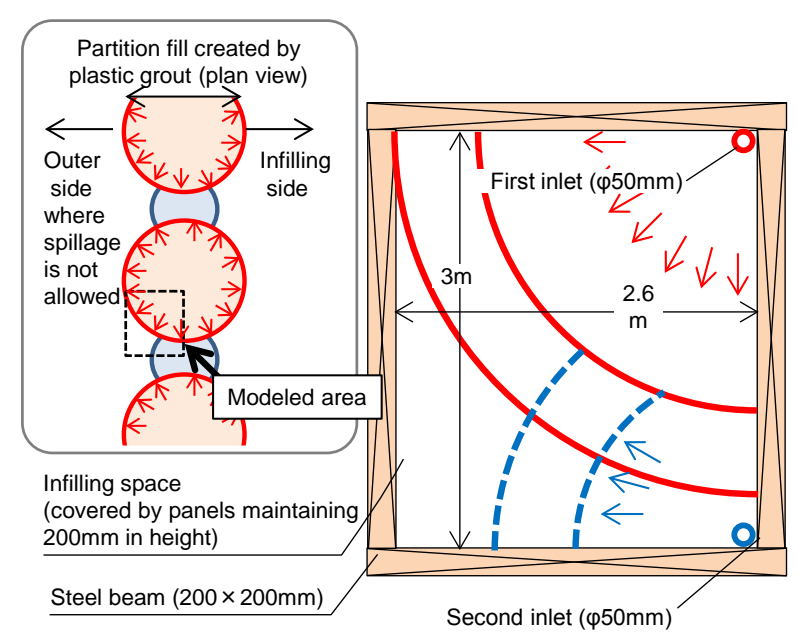

Fig. 5. Plan view of Test 2.

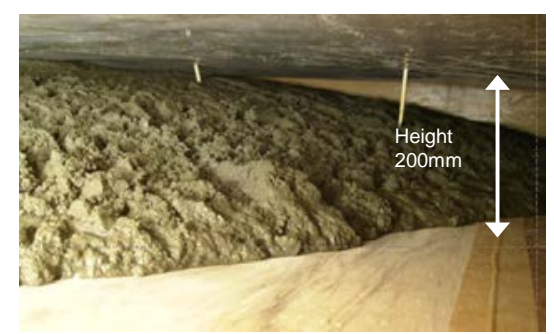

Fig. 6. Tip of plastic grout during the first infilling step.

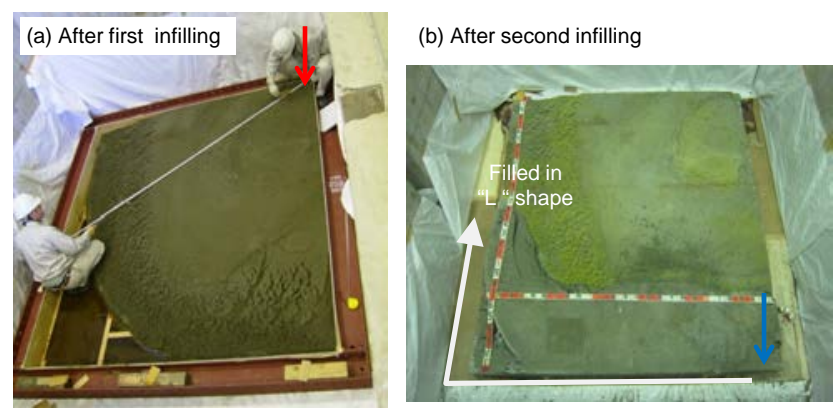

Fig. 7. Observations of Test 2 after removal of cover panel.

the infilling circle reached the other corner. The next day, the second step of infilling work was carried out through $50 \mathrm{~mm}$ inlet in the second corner with a stiffer grout (approximately $80 \mathrm{~mm}$ in flow). Grouting continued until the tip of the grout reached the opposite side of the infilling space. The only reason for using the stiffer mixture was experimental; to clarify the difference between the first and second infilling steps.

Fig. 7 shows the infilling results after the first and second steps of infilling, respectively. The first step achieved a circle of grouting. The full height of 200 $\mathrm{mm}$ was entirely filled with the grout up to approximately $2.2 \mathrm{~m}$ from the inlet. The second step of infilling achieved an " $\mathrm{L}$ " shape from the second inlet.

Changes in infilling pressure through the both first and second steps are illustrated and discussed in the next chapter along with the numerical assessment.

\section{NUMERICAL ASSESSMENT}

\subsection{Outline of numerical analysis}

Numerical fluid analysis is used in a wide variety of engineering fields. In the scenario considered here, infilling using plastic grout, it offers a theoretical picture of infilling behavior that contributes to understanding of both experimental and practical infilling behavior. One of the authors has previously examined the applicability of two and three-dimensional numerical simulations to an infilling test using a space measuring $10 \mathrm{~m} \times 1 \mathrm{~m}$ x $500 \mathrm{~mm}$ (Ishii et. al. (2010a), Ishii et. al. (2010b)). In this study, numerical simulations of both the Test 1 and Test 2 are carried out.

The proposed method of numerical fluid analysis consists of three-dimensional Navier-Stokes equations and an incompressible equation. The plastic grout is modeled as a Bingham fluid and the surrounding air/water is set as Newtonian fluid. Boundary between the plastic grout and surrounding air/water is expressed numerically and the infilling process is simulated in steps by identifying velocities and pressures in each cubic element.

Numerical simulations of cylinder flow with changing grout viscosity have been carried out previously (Ishii and Kitazume (2012)) showing that the numerical results reproduce cylinder flow behavior when vane shear strength of the grout is set as the yield stress of the Bingham fluid. Based on this earlier study, the yield stress was set at 400 and $600 \mathrm{~N} / \mathrm{m}^{2}$ for the mixtures with flow characteristics of 100 and $80 \mathrm{~mm}$ respectively in the following analysis.

\subsection{Analysis of Test 1}

The three-dimensional model of Test 1 is shown in Fig. 8. The analysis covered an overall size of $5 \mathrm{~m} \times 7$ $\mathrm{m}$ and $500 \mathrm{~mm}$ in height. Each cubic element measures $0.175 \mathrm{~m} \mathrm{x} 0.161 \mathrm{~m}$ on the plan and $0.125 \mathrm{~m}$ in height. The element of the position of the inlet was set with a uniform velocity representing an infilling rate equivalent to the experimental condition. This was calculated as follows:

The plane area of the inlet element is $0.175 \mathrm{~m} \mathrm{x}$ $0.161 \mathrm{~m}=0.0282 \mathrm{~m}^{2}$ and the required (experimental) infilling rate is $300 \mathrm{~L} / \mathrm{min}=0.3 \mathrm{~m}^{3} / \mathrm{min}=0.005 \mathrm{~m}^{3} / \mathrm{sec}$, Thus the velocity giving an equivalent infilling rate is $0.005 / 0.0282=0.0177 \mathrm{~m} / \mathrm{sec}$.

The entire boundary was set as a non-slip surface, except the opposite face, which was made free. Elements representing the mound were set as fixed elements, with a non-slip surface. Another analysis was also conducted using a model without the mound in order to confirm the influence of the mound on filling behavior.

The infilling process was numerically obtained as shown in Fig. 9. The diagrams represent the elements occupied by grout as sphere plots. The entire space, 
including the far side of the mound, became filled with the grout as time passed.

The arrival times of the grout in the analysis and in the infilling test are summarized in Fig. 10, where they are plotted against distance from the inlet. The solid line in the diagram represents the calculated result when infilling progress is assumed to be simple: the grout initially expands in a circle, then touches the rear and the side boundaries, and finally the tip of the grout moves toward the front only. Fig. 10 shows that the arrival times obtained in the infilling test coincide closely with the analytical result.

Fig. 11 shows the change in infilling pressure obtained in both the infilling test and the analysis (with and without the mound). In the test the grout pressure was recorded manually from a pressure gauge fitted on the grout pipe leading the inlet. Since the grout pipe was not modeled in the analysis and there is no analytical representation of it, changes in pressure at the inlet element are compared with that experimentally observed. Even though the measured pressure values are rough, the simulated results reflect the general trend. Both analytical and experimental pressure curves show a change after 20 minutes, when the grout reached the mound, even though temporary decreases occurred in the infilling test at 25 - 30 minutes.

\subsection{Analysis of Test 2}

The analytical model of Test 2 consists of cubic elements measuring $0.10 \times 0.10 \times 0.025 \mathrm{~m}$ in size. The first infilling step was simulated as in the simulation of Test 1 , setting the equivalent velocity to the infilling rate at the first inlet and employing $400 \mathrm{~N} / \mathrm{m}^{2}$ as for the yield stress of the viscous model of the grout. To simulate the second infilling step, cubic elements that

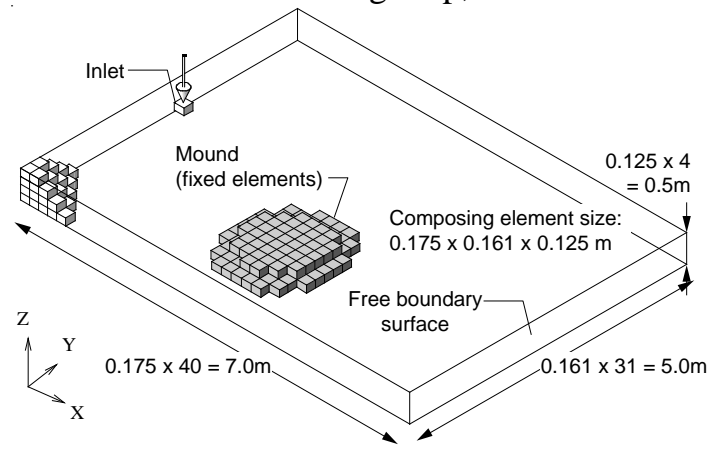

Fig. 8. Numerical modeling of Test 1.
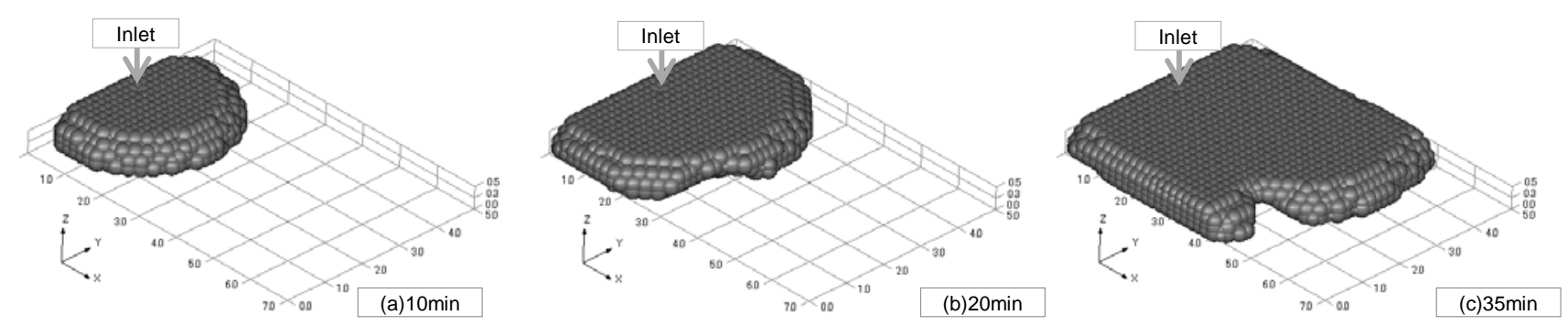

had been occupied during the first infilling step were set as fixed elements in a similar way to the mound in Test 1 . Then the appropriate equivalent velocity was set at the second inlet to simulate the second infilling step, with $600 \mathrm{~N} / \mathrm{m}^{2}$ set as the yield stress of the viscous model of the grout. Two different boundary conditions, non-slip and slip were analyzed for bottom and top boundaries as explained later.

The analysis replicated the first infilling step; the grout spreads in circular from the corner in which the first inlet is located. The area over which the grout filled to the top of the filling space is equivalent to that observed in the test. The inlet pressure during the first infilling step is compared with measured values in Fig. 12(a). The analysis reproduced the measured spread even some fluctuations were observed in early and middle stage of the work.

The second infilling step was depicted in Fig. 13, with (a) non-slip and (b) slip boundary conditions. With both boundary conditions, the area around the second inlet was filled with grout to the whole height for both the boundary conditions. However, the final shape of

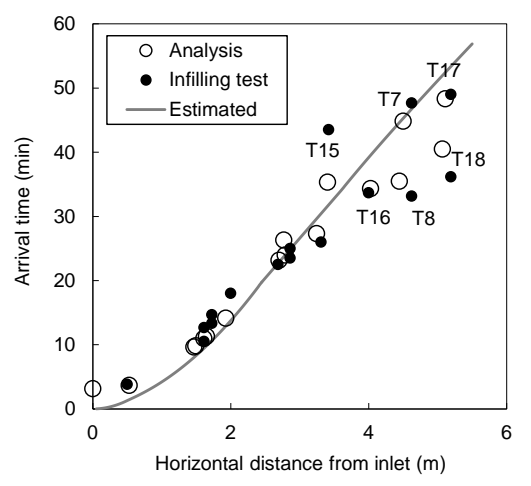

Fig. 10. Relationship between distance from inlet and arrival time (Test 1)

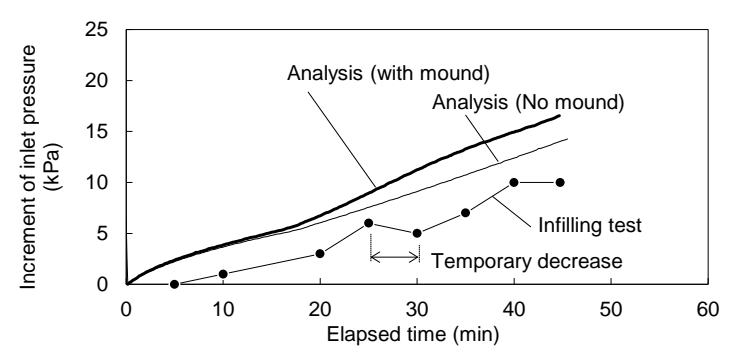

Fig. 11. Comparison of inlet pressures between test and analysis (Test 1).

Fig. 9. Simulated infilling process (Test 1). 

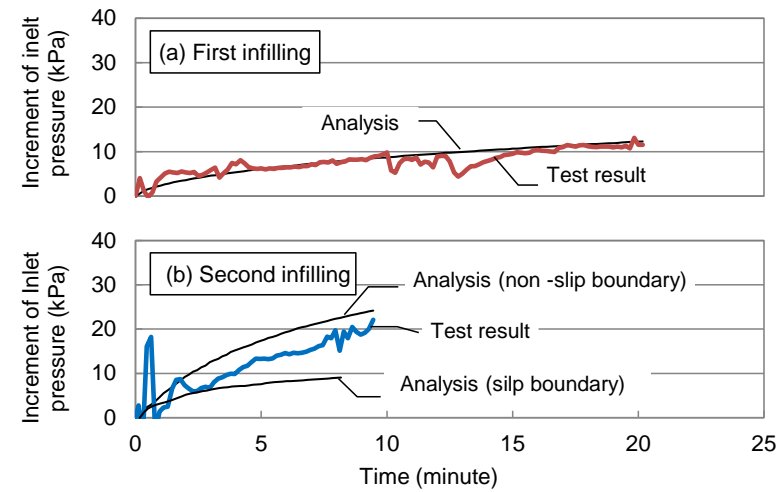

Fig. 12. Comparison of inlet pressure between Test 2 and analysis.

the filled grout became different by the end. The analytical results with slip boundary conditions are most similar to observed pattern seen in Fig.7 (b). It is clear that actual surface roughness of the solidified first-step grout and that of the wooden panels used for the base and cover are totally different. The results imply that surface roughness has a significant influence on filling shape, resulting in variations in the quantity of material necessary for filling individual partitions.

The observed changes in inlet pressure during the second infilling step are compared with analysis in Fig. 12(b). For the same reason as given in relation to Fig.11, pressure changes are compared, not absolute pressure. The observed result lies between the analytical results for the non-slip and slip boundary conditions, and follows the similar trend. Though there is still room to investigate the boundary treatment and improve the setting of the analytical conditions, this analysis yields the estimated inlet pressure to a certain degree of accuracy.

\section{CONCLUDING REMARKS}

Through an experimental study involving two infilling tests, it was demonstrated that plastic grout can fill the entire height of the simulated infilling voids when filled by both single step from one inlet and two steps from neighboring inlets. Proposed method of numerical analysis was able to reproduce the infilling behavior of the plastic grout in both tests. The results suggest that setting of boundary slip conditions significantly influences on the simulated infilling behavior and inlet pressure.

Direct observation of voids being filled is normally not enough during actual site operations, so changes in inlet pressure are often the effective information available about the ongoing process. We believe that analytically obtained predictions of infilling behavior offer a good index for assessing proper infilling progress, and can therefore contribute to more reliable void-filling work.

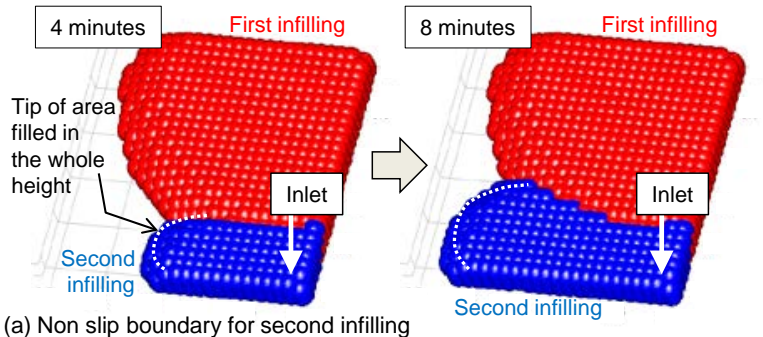

(a) Non slip boundary for second infilling

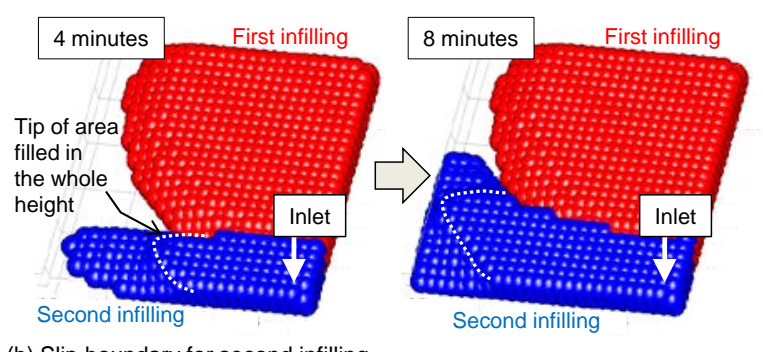

(b) Slip boundary for second infilling

Fig. 13. Simulated infilling process (Test 2, second infilling step).

\section{REFERENCES}

1) Ishii, H., Hikgaki, K., Ito, K., Kimura, M. and Koyama, F. (2010a): Application of Numerical Fluid Analysis to Void Filling Injection with Use of Hydraulic Plastic Grout, Journal of Japan Society of Civil Engineers, F, Vol.66, No.1, 170-180 (in Japanese).

2) Ishii, H., Ito K. and Higaki, K. (2010b): Numerical Fluid Analysis of Hydraulic Plastic Grout for Work Performance Estimation, Technical Report of Taisei Technology Center, No.43 (in Japanese).

3) Ishii, H., Kimura, M., Koyama, F. (2011): Construction of immersed tunnel foundation using plastic grout, Proceedings of 15th Asian Regional Conference on Soil Mechanics and Foundation Engineering.

4) Ishii, H. and Kitazume, M. (2012): Numerical simulation of hydraulic plastic grout subjected to cylinder flow test, and estimation of its rheological properties, Proceedings of 47th annual conference of Japanese Geotechnical Society, 565-567 (in Japanese)

5) Ito, K., Oda, Y., Ishii, H., Yamaguchi T., Toyama M., and Nakatsuka K. (2011): Advanced marine works for deepwater immersed tunnel in the Bosphorus Strait, Coastal Structures 2011, 1177-1188, DOI: 10.1142/9789814412216_0102.

6) Ohtani, J., Ishihara, K., Yokoyama, H., Mizutani, A., Imura, N., Ishii, H. and Imamura, N. (2014): Infilling under piled slab, part III infilling work and post examination, Proceedings of 68th annual conference of Japan Society of Civil Engineers, 1326-1327 (in Japanese).

7) Sakamoto, A., Sugiura, K., Yamada, N. and Iwaki, K. (2006): Development and Applications of Limited Area Filling Techniques for Abandoned Underground Cavities, Journal of Japan Society of Civil Engineers, Vol.62, No.3, 546-557 (in Japanese).

8) Yasui, T., Shimizu, H., Oguma, N. and Fuseya M. (2011): Development of Cave Filling Method with Plastic Grout, Technical Report of Maeda Corporation, Vol. 52 (in Japanese). 